\title{
Thyrolipomatosis: A case report with review of the literature
}

\author{
MITSUAKI ISHIDA ${ }^{1}$, IPPEI KASHU ${ }^{2}$, TSUYOSHI MORISAKI ${ }^{3}$, MASAO TAKENOBU $^{3}$, \\ SUEYOSHI MORITANI ${ }^{3}$, YOSHIKO UEMURA ${ }^{1}$ and KOJI TSUTA ${ }^{1}$ \\ ${ }^{1}$ Department of Pathology and Laboratory Medicine, Kansai Medical University, Hirakata, \\ Osaka 573-1010; ${ }^{2}$ Division of Diagnostic Pathology and ${ }^{3}$ Department of Otolaryngology and \\ Head and Neck Surgery, Kusatsu General Hospital, Kusatsu, Shiga 525-0066, Japan
}

Received December 12, 2016; Accepted March 15, 2017

DOI: $10.3892 / \mathrm{mco} .2017 .1249$

\begin{abstract}
Fatty tissue is not usually present within the thyroid gland. Only a few fat-containing thyroid lesions have been reported to date, and thyrolipoma is the most common fat-containing lesion of the thyroid gland. Thyrolipomatosis is a condition characterized by diffuse mature adipose cell infiltration of the normal thyroid gland. In this report, we describe what is, to the best of our knowledge, the 12th documented case of thyrolipomatosis, and review the fat-containing lesions of the thyroid gland. A 68-year-old Japanese woman presented with a neck mass that had first been noticed $\sim 7$ years earlier. A computed tomography scan revealed diffuse thyroid gland enlargement and total thyroidectomy was performed. The histopathological examination revealed that mature fatty tissue was diffusely distributed throughout the thyroid gland, as well as among the hyperplastic follicles. Capsular formation or amyloid deposition were not observed. Nuclear grooves or intranuclear cytoplasmic inclusions were not observed. Accordingly, thyrolipomatosis was diagnosed. Albeit rare, various neoplastic and non-neoplastic thyroid lesions may contain mature fatty tissue. Therefore, thyrolipomatosis must be included in the differential diagnostic consideration of fat-containing lesions of the thyroid gland.
\end{abstract}

\section{Introduction}

Although there is usually no mature fatty tissue within the thyroid gland, fat-containing thyroid lesions have been reported (1). Fat-containing thyroid lesions may be classified into two groups, namely neoplastic and non-neoplastic lesions. Thyrolipoma, also referred to as lipoadenoma, is the most common fat-containing lesion of the thyroid gland; it is

Correspondence to: Dr Mitsuaki Ishida, Department of Pathology and Laboratory Medicine, Kansai Medical University, 2-5-1 Shinmachi, Hirakata, Osaka 573-1010, Japan

E-mail: ishidamt@hirakata.kmu.ac.jp

Key words: thyrolipomatosis, adipose cell, thyroid considered to be a variant of follicular adenoma and is characterized by the presence of mature adipose cells interspersed throughout the follicular adenoma (2). Moreover, a few cases of papillary carcinoma and follicular carcinoma with adipose cells have been reported (1). Non-neoplastic fat-containing thyroid lesions include amyloid goiter and Hashimoto thyroiditis $(1,3)$.

Albeit extremely rare, diffuse mature adipose cell infiltration of the normal thyroid gland has been previously reported, referred to as thyrolipomatosis or diffuse lipomatosis of the thyroid gland (2). To the best of our knowledge, only 11 cases have been documented in the literature to date $(2,4-8)$. We herein describe an additional case of thyrolipomatosis and review the fat-containing thyroid lesions.

\section{Case report}

A 68-year-old Japanese woman with a past history of diabetes mellitus and angina pectoris presented at the Kusatsu General Hospital in August 2016 with a neck mass that had been noticed $\sim 7$ years earlier. A computed tomography scan revealed diffuse thyroid gland enlargement, compressing the trachea, with multiple calcifications in the bilateral lobes. The serum thyroid-stimulating hormone and free thyroxine (FT4) levels were within the normal range $(0.63 \mu \mathrm{IU} / \mathrm{ml}$, range $0.4-4.0 \mu \mathrm{IU} / \mathrm{ml}$; and $1.01 \mathrm{ng} / \mathrm{dl}$, range $0.8-1.7 \mathrm{ng} / \mathrm{dl}$, respectively), but the free triiodothyronine (FT3) level was mildly decreased $(1.84 \mathrm{pg} / \mathrm{ml}$, range $2.2-4.1 \mathrm{pg} / \mathrm{ml})$. Total thyroidectomy was performed.

The postoperative course was uneventful and the patient has been free from tumor recurrence and metastasis during the 3 months of medical follow-up.

The formalin-fixed, paraffin-embedded tissue blocks of the resected thyroid specimens were cut into $3-\mu \mathrm{m}$ sections, deparaffinized and rehydrated. Each section was stained with hematoxylin and eosin.

Histopathological examination of the thyroid gland revealed that mature fatty tissue was diffusely distributed throughout the gland (Fig. 1A). Capsular formation was not observed, and the follicular cells had small round nuclei without nucleoli (Fig. 1B). Nuclear grooves or intranuclear cytoplasmic inclusions were not observed. Hyperplastic follicles were noted, and mature fatty cells were also present among the hyperplastic 

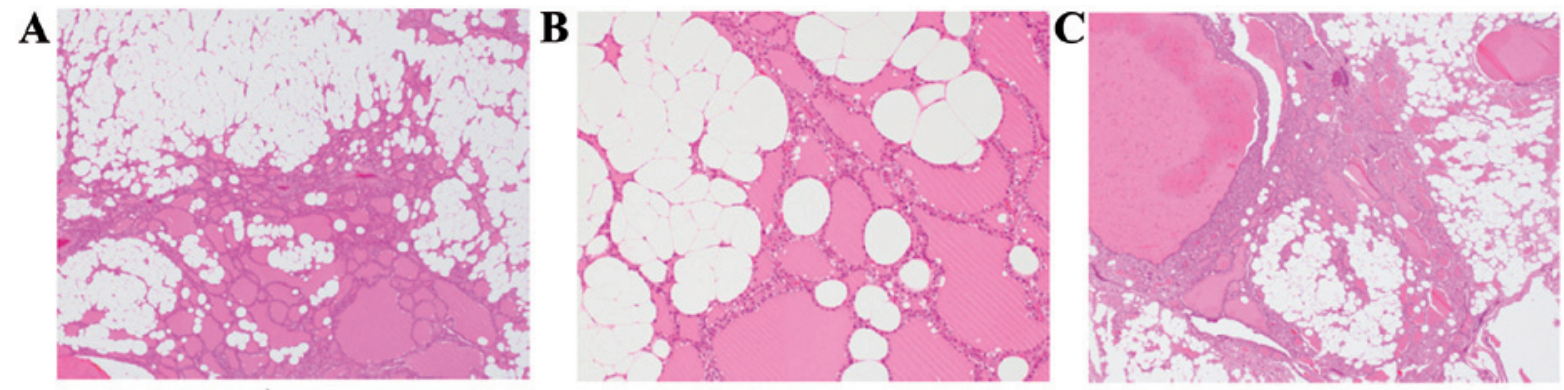

Figure 1. Histopathological findings of the thyroid gland. (A) Diffuse infiltration by mature fatty cells within the thyroid follicles was observed [hematoxylin and eosin staining (H\&E); original magnification, x40]. (B) The fatty cells and the follicular cells were not atypical (H\&E; original magnification, x200). (C) Fatty infiltration was also observed in the hyperplastic follicles (H\&E; original magnification, $\mathrm{x} 40$ ).

follicles (Fig. 1C). Focal stromal sclerosis and calcifications were identified. Amyloid deposition and lymphoplasmacytic infiltration were not observed.

Based on these findings, thyrolipomatosis was diagnosed.

\section{Discussion}

In this report, we describe what is, to the best of our knowledge, the 12th case of thyrolipomatosis documented to date. Ge et al summarized the clinicopathological characteristics of 10 cases of thyrolipomatosis (2). According to their review, the median age of the patients was 42 years (range, 11-76 years) and the gender distribution was almost equal. The common complaint was diffuse or nodular goiter, with or without compression symptoms. The patients usually presented with little change in thyroid function (2). The clinicopathological characteristics of the present case were consistent with those of previously reported cases.

The characteristic pathological feature of thyrolipomatosis is the presence of diffuse mature adipose cell infiltration among the non-neoplastic thyroid follicles. Although no fibrous capsule formation has been reported, stromal fibrosis and lymphocytic infiltration may be occasionally observed (2). Ge et al classified fat-containing thyroid lesions into three categories: i) Nodular pattern (thyrolipoma), ii) diffuse pattern (the adipose tissue is diffusely distributed throughout the thyroid gland, the thyroid gland is composed of unremarkable follicles, and fat infiltration is also present in adenomatous nodules), and iii) combined nodular and diffuse pattern (presence of thyrolipoma, with diffuse fatty infiltration also noted in the thyroid tissue surrounding the thyrolipoma) (2). In the present case, fatty infiltration was observed throughout the bilateral lobes of the thyroid, and it was also present in the hyperplastic thyroid nodules, without follicular adenoma. Therefore, this case exhibits the diffuse pattern (thyrolipomatosis) according to the classification proposed by Ge et al (2).

The mechanism underlying fatty infiltration of the thyroid gland remains unclear. A hypothesis involving a metaplastic process has been suggested. Fatty tissue may be derived from metaplasis of stromal fibroblasts, possibly in response to chronic tissue hypoxia or senile involution $(1,2,9)$. However, the detailed mechanism has not been elucidated; therefore, additional studies are required to determine the mechanism underlying the occurrence of this rare lesion.
Table I. Summary of fat-containing lesions of the thyroid gland.

\begin{tabular}{ll}
\hline Neoplastic & \multicolumn{1}{c}{ Non-neoplastic } \\
\hline Thyrolipoma & Amyloid goiter \\
Papillary carcinoma & Adenomatous nodule \\
Follicular carcinoma & Thyrolipomatosis \\
& Dyshormonogenetic goiter \\
& Lymphocytic thyroiditis \\
\hline
\end{tabular}

Neoplastic as well as non-neoplastic thyroid lesions may contain mature fatty tissue. The fat-containing thyroid lesions are summarized in Table I. The neoplastic lesions comprise thyrolipoma, papillary carcinoma and follicular carcinoma, whereas the non-neoplastic lesions include adenomatous nodule, thyrolipomatosis, amyloid goiter, dyshormonogenetic goiter and Hashimoto's thyroiditis (1). Thyrolipomatosis must be differentiated from the other abovementioned lesions. Thyrolipoma is the most common fat-containing lesion of the thyroid gland (1). The characteristic histopathological feature is the presence of mature fatty tissue in the follicular adenoma and a fibrous capsule is present around the tumor $(1,2)$. Amyloid goiter is also a relatively common fat-containing non-neoplastic thyroid lesion (3). The presence of amyloid among the non-neoplastic thyroid follicles is characteristic of this condition, and special staining may help with the differential diagnosis. Papillary carcinoma and follicular carcinoma with mature fatty tissue have a characteristic carcinomatous component; therefore, the diagnosis may not be difficult (1). Furthermore, lipid-rich follicular neoplasms, in which intracellular lipid is present in the cytoplasm of the neoplastic follicular cells, must be differentiated from thyrolipomatosis $(1,2)$.

In conclusion, the present report describes the 12th case of thyrolipomatosis documented to date. Albeit rare, fatty infiltration may occur in various neoplastic and non-neoplastic thyroid lesions. Therefore, the abovementioned lesions must be considered in the differential diagnosis of thyrolipomatosis.

\section{References}

1. Gnepp DR, Ogorzalek JM and Heffess CS: Fat-containing lesions of the thyroid gland. Am J Surg Pathol 13: 605-612, 1989. 
2. Ge Y, Luna MA, Cowan DF, Truong LD and Ayala AG: Thyrolipoma and thyrolipomatosis: 5 case reports and historical review of the literature. Ann Diagn Pathol 13: 384-389, 2009.

3. Himmetoglu C, Yamak S and Tezel GG: Diffuse fatty infiltration in amyloid goiter. Pathol Int 57: 449-453, 2007.

4. Chesky VE, Dreese WC and Hellwig CA: Adenolipomatosis of the thyroid: A new type of goiter. Surgery 34: 38-45, 1953.

5. Asirwatham JE, Barcos M and Shimaoka K: Hamartomatous adiposity of thyroid gland. J Med 10: 197-206, 1979.

6. Simha MR and Doctor VM: Adenolipomatosis of the thyroid gland. Indian J Cancer 20: 215-217, 1983.
7. Arslan A, Alíç B, Uzunlar AK, Büyükbayram H and Sari I: Diffuse lipomatosis of thyroid gland. Auris Nasus Larynx 26: 213-215, 1999.

8. Sanuvada RV, Chowhan AK, Rukmangadha N, Patnayak R, Yootla M and Amancharla LY: Thyrolipomatosis: An inquisitive rare entity. Gland Surg 3: E6-E9, 2014.

9. Schröder S and Böcker W: Lipomatous lesions of the thyroid gland: A review. Appl Pathol 3: 140-149, 1985. 